\title{
Influence of Temperature and Iron Phosphate on the Effect of Poplar Sawdust Filter on Biogas Slurry
}

\author{
Jiawei Zhang, 2, a, Lianmei Wei, b, Fangjing Sun ${ }^{1, c}$ and Lijun Wang ${ }^{1,2, d}$ \\ ${ }^{1}$ School of Environmental and Materials Engineering, Shanghai Polytechnic University, Shanghai \\ 201209, P.R .China. \\ ${ }^{2}$ Research Center of Resource Recycling Science and Engineering, Shanghai Polytechnic \\ University, Shanghai 200444, China.
}

a571840845@qq.com, bweilianmei@yahoo.com, c1262988164@qq.com, dLjwang@sspu.edu.cn

\begin{abstract}
The carbonized plant powder and the purified phosphating slag are used to filter the biogas slurry, and the filtered residue and filtrate are rationally used to solve the environmental pollution caused by the discharge of the biogas slurry and phosphating slag. The three plant powders (corn straw, wheat straw, and poplar wood shavings) were completely carbonized at the same temperature, and poplar sawdust showed the best filtration performance for biogas slurry. The carbonization of poplar sawdust and FePO4 mixed filter material was carried out at different temperatures to form organic filter media and the biogas slurry was filtered. The results of the study show that as the temperature increases, the filtration rate decreases, but the turbidity also decreases, suggesting that the filtration effect is better. The concentration of water-soluble total phosphorus in the filtrate is highest at $150^{\circ} \mathrm{C}$ and can be used as a liquid fertilizer.
\end{abstract}

Keywords: Biogas slurry,Poplar sawdust,Ferric phosphate,Phosphorus.

\section{Introduction}

With the increasing depletion of fossil resource and the aggravation of environmental pollution, biogas fermentation technology has attracted more attention due to its renewable and environmentally friendly performance [1]. As a great agricultural country, more and more biogas digesters have been built in recent years [2]. The biogas digesters also produce anaerobic fermentation residue, i.e. biogas slags and slags, while producing combustible gas [3]. However, people pay more attention to the environmental pollution, which caused by the random discharge of biogas slurry and biogas slags [4]. Therefore, it is necessary to effectively and reasonably utilize fermented residue, and to develop the ecological and sustainable rural areas [5].As we all know, biogas slurry, as the liquid part of the anaerobic fermentation residue, preserves $90 \%$ of the nutrients, which shows excellent fertilizer efficiency and could be used to disinfected [6-7]. The biogas slurry has been accepted by people and used in agricultural industry due to its broad application prospect [8-9].

As a kind of non-renewable resource, phosphorus is consumed a lot every year, because phosphate ore is being continuously exploited to be used as fertilizer. However, the distribution of phosphate rock in the world is extremely uneven, China, Morocco, the United States and Russia together account for more than 70 percent of the total phosphate [10]. The phosphate ore will be exhausted in the next hundred years at the current depletion rate. Thus, it is the key point that how to use phosphorus element wisely. With the continuous progress of industrialization, the phosphating is becoming indispensable for building decoration and metal surface protection. But the resulting phosphating residue was regarded as hazardous waste due to its strong acidity, high phosphorus content and the presence of some heavy metal ions in the sludge from the phosphating solution [11]. Moreover, the phosphating residue will influence phosphating quality even prevent phosphating film formation on the metal surface [12]. More importantly, as the major component of phosphating residue, iron phosphate has many advantages in many applications [13]. The conventional methods for treating the phosphate residue are landfill, and solidification and vitrification, which are expensive and environmentally unfriendly, as a large amount of energy is consumed [14]. Therefore, it is important that a more reliable and economical strategy be developed to recover the major components of phosphate residue [15-17]. The direct discharge of phosphating slag not only result in environmental 
pollution, but also wasting of resources. Thus, it is a challenge to treat phosphating slag from waste to treasure, which is in line with the needs of social development. For these reasons, it would be very powerful if the materials collected from waste residues could be used to remediate other environmental concerns.

Filtration technology of biogas slurry has been investigated a lot in recent years, which has big application space [18-22]. It is well known that biological organic matter contains a lot of humic acid, which is helpful for the release of phosphorus in iron phosphate [23]. Consequently, the filtered filtrate can be used as liquid fertilizer for agricultural development, which not only relieve the environmental pressure caused by the random discharge of filtrate and phosphating slag, but also take advantage of the nutrients in both wastes. The project is very meaningful and will achieve a goal of wastes treatment with processes of wastes against one another.

In this study, we firstly mixed poplar sawdust with phosphating residue purified by high pressure solution method. Then the mixture was carbonized at different temperature. Finally, we monitored the effect of biogas slurry filtration by different materials. To the best of our knowledge, such an approach has not been reported in any previous publications. We also detected the soluble total phosphorus content in the filtrate and examine the performance of liquid fertilizer. It provides a new method for the resource utilization of biogas slurry and phosphating slag.

\section{Materials and Methods}

\subsection{Materials}

Phosphate residue was supplied by an auto components company in Zhejiang, China. The biogas slurry and poplar sawdust were supplied by a biological energy company in Shandong, China. Ascorbic acid (Analytical reagent (AR), $\geq 99.7 \%$ ), Ammonium molybdate tetrahydrate (Analytical reagent (AR), $\geq 99 \%$ ), Antimony potassium tartrate (Analytical reagent (AR), $\geq 99 \%$ ), $\mathrm{H}_{2} \mathrm{SO}_{4}$ (Analytical reagent (AR), $\geq 98 \%$ ), and Monopotassium phosphate (Guarantee reagent (AR), $\geq 99.8 \%$ ),

\subsection{Characterization Methods}

The chemical composition of the phosphate residue and purified sample was analyzed by an Xray fluorescence spectrometer (XRF) (XRF-1800, Shimadzu Corporation, Japan). The morphology of the samples was characterized by scanning electron microscopy (SEM) (S-4800, Hitachi Corporation, Japan) with the accelerating voltage at $10 \mathrm{kV}$ and current at $10 \mathrm{~mA}$. X-ray diffraction (XRD) (D8-Advance, Bruker Corporation, Germany) measurements were undertaken to record the phase composition and crystalline structure of the powder samples, operating at $40 \mathrm{kV}$ and $40 \mathrm{~mA}$ with a monochromatized $\mathrm{Cu} \mathrm{K \alpha}$ radiation $(\lambda=0.15418 \mathrm{~nm})$ source. The UV-vis reflectance spectra of the samples were analyzed by a UV-vis spectrophotometer (UV2550, Shimadzu Corporation, Japan). $\mathrm{BaSO}_{4}$ was used as a reflectance standard.

\subsection{Experiments Method}

The procedures used to prepare the purified phosphating residue as described as following: Specifically, $20 \mathrm{~g}$ phosphate residue and $2 \mathrm{~g} \mathrm{H}_{3} \mathrm{PO}_{4}$ were mixed with $20 \mathrm{~g}$ deionized water in a beaker at $80^{\circ} \mathrm{C}$ by high pressure solution method. After stirring for $4 \mathrm{~h}$, the product was filtered and washed with deionized water until the $\mathrm{pH}$ reached 7 , then dried at $80^{\circ} \mathrm{C}$ overnight. In order to ensure the purity of the sample, this purification process was repeated three times to remove zinc and calcium phosphate. Subsequently, iron phosphate was added with poplar sawdust and then grinded. Finally, the mixture was carbonized at $150^{\circ} \mathrm{C}, 250^{\circ} \mathrm{C}, 350{ }^{\circ} \mathrm{C}, 450^{\circ} \mathrm{C}$ respectively ${ }^{[24-26]}$, and were used to filter biogas slurry. 
Table. 1 Experimental program

\begin{tabular}{ccccc}
\hline & $\begin{array}{c}\text { Temperature } \\
\left({ }^{\circ} \mathrm{C}\right)\end{array}$ & $\begin{array}{c}\text { Material } \\
(\mathrm{g})\end{array}$ & $\begin{array}{c}\text { Filtration pressure } \\
(\mathrm{N})\end{array}$ & Filter time $(\mathrm{min})$ \\
\hline 1 & 25 & 20 & 20 & 30 \\
2 & 150 & 20 & 20 & 30 \\
3 & 250 & 20 & 20 & 30 \\
4 & 350 & 20 & 20 & 30 \\
5 & 450 & 20 & 20 & 30 \\
\hline
\end{tabular}

\section{Results and Discussion}

\subsection{Composition Analysis Purified Phosphating Residue}

The content of iron phosphate can be tested by CSM 08012603-2005 (Blast furnace slag determination of total iron content - EDTA titration) according to national standard method. Firstly, $0.2 \mathrm{~g}$ of iron phosphate was measured to mix with concentrated hydrochloric acid in a $250 \mathrm{~mL}$ beaker. Then, the cold solution was transferred to $250 \mathrm{mLvolumetric}$ flask and measured $25.00 \mathrm{mLsolution}$ in a conical flask with addition of ammonium hydroxide $(1+1)$ and hydrochloric acid $(1+1)$, to get $\mathrm{pH}=$ 1. Finally, $3 \mathrm{~mL}$ sulfonyl salicylic acid solution was added to the conical flask at $60 \sim 70^{\circ} \mathrm{C}$, and the solution was titrated by $0.005 \mathrm{~mol} / \mathrm{L}$ EDTA till the solution showed luminous yellow or transparency.

The content of phosphorus of iron phosphate can be tested by GB 11893-1989 (Determination of total phosphorus in water by ammonium molybdate spectrophotometry) according to national standard method. Firstly, $25.00 \mathrm{~mL}$ treated solution by concentrated hydrochloric acid was measured to mix with $1 \mathrm{~mL}$ ascorbic acid. Then the molybdate was added after 30 seconds and stirred evenly. After $15 \mathrm{~min}$ in the room temperature, the absorbance of solution was calculated at the wave length of $700 \mathrm{~nm}$ on the ultraviolet and visible spectrophotometer.

As shown in Table 2, the purity of $\mathrm{FePO}_{4}$ has improved $17.72 \%$ after three cycles of acid leaching.

The content of iron phosphate is calculated as following formula, in terms of mass fraction:

$$
W_{F_{e} P_{+}}=\frac{C_{E D T A} \times V \times 55.85}{m \times 1000} \times \frac{150.82}{55.85} \times 100 \%
$$

$W$ FePO4 - Mass fraction of $\mathrm{FePO}_{4}, \%$;

$C_{\text {EDTA }}-$ Concentration of standard EDTA solution, $0.005 \mathrm{~mol} / \mathrm{L}$;

$\mathrm{V}$ — Volume of standard EDTA solution, $\mathrm{mL}$;

$\mathrm{m} \longrightarrow$ Mass of the raw material, $0.20 \sim 0.50 \mathrm{~g}$;

55.85 Molar mass of Fe, g/mol;

$150.82 \longrightarrow$ Molar mass of $\mathrm{FePO}_{4}, \mathrm{~g} / \mathrm{mol}$.

Table. 2 Composition before and after purification

\begin{tabular}{cccc}
\hline Samples & $\mathrm{Fe}$ & $\mathrm{P}$ & $\mathrm{FePO}_{4}$ \\
\hline Phosphating residue $/ \%$ & 29.46 & 20.66 & 79.34 \\
Purified $\mathrm{FePO}_{4} / \%$ & 35.28 & 20.08 & 95.02 \\
\hline
\end{tabular}

\subsection{Characterization of $\mathrm{FePO}_{4}$}

We also find that the $\mathrm{FePO}_{4}$ showed white and yellow before and after calcination. It can be seen from Fig.1, there is no impurity on the surface of the aggregate compound particle structure. The diameter of small particle is about $1 \mu \mathrm{m}$, while the diameter of agglomerated particle achieved $13 \mu \mathrm{m}$. Comparing to sample after calcination, the sample is smaller and the diameter reduced to $7 \mu \mathrm{m}$ as shown in Fig.2, which could be the fact that the crystal water in sample lost at high temperature. 


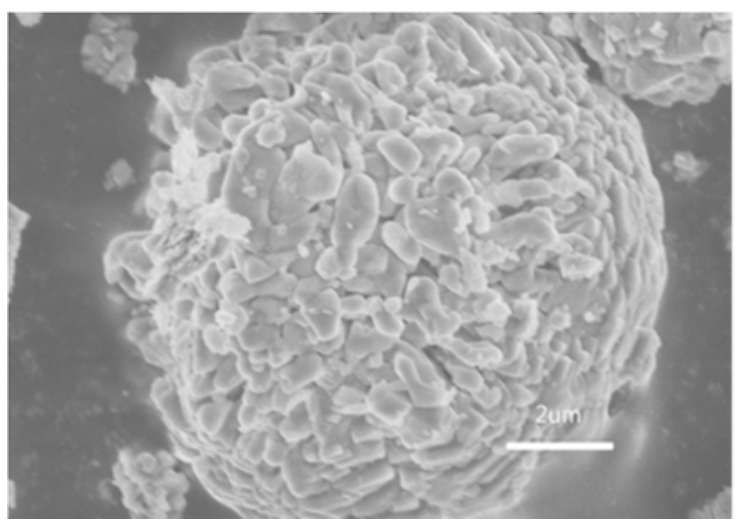

Fig.1 SEM diagram before calcination

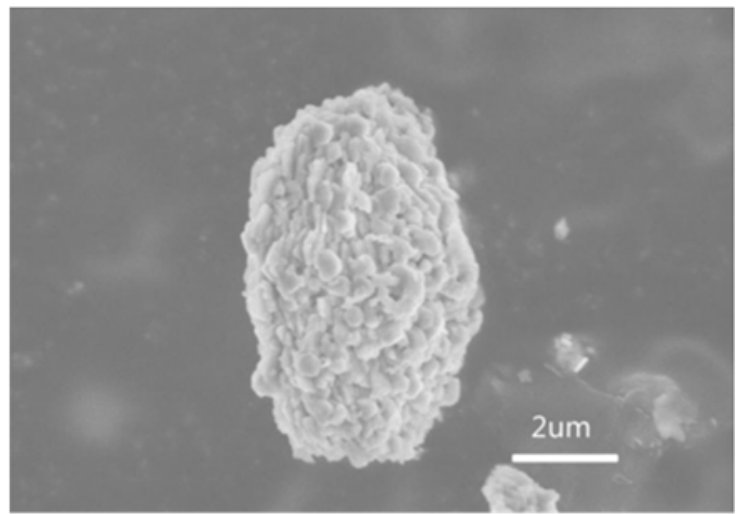

Fig.2 SEM diagram after calcination

A comparison between the XRD patterns of the phosphating residue and the purified sample is shown in Fig. 3. It can be seen from XRD image that the phosphating residue showed a similar peak position to $\mathrm{FePO}_{4} \cdot 2 \mathrm{H}_{2} \mathrm{O}$ corresponding to $\mathrm{PDF} \# 33-0666$. However, the sample showed stronger peaks and smaller half peak width, which suggested that the main component of purified sample is $\mathrm{FePO}_{4} \cdot 2 \mathrm{H}_{2} \mathrm{O}$.

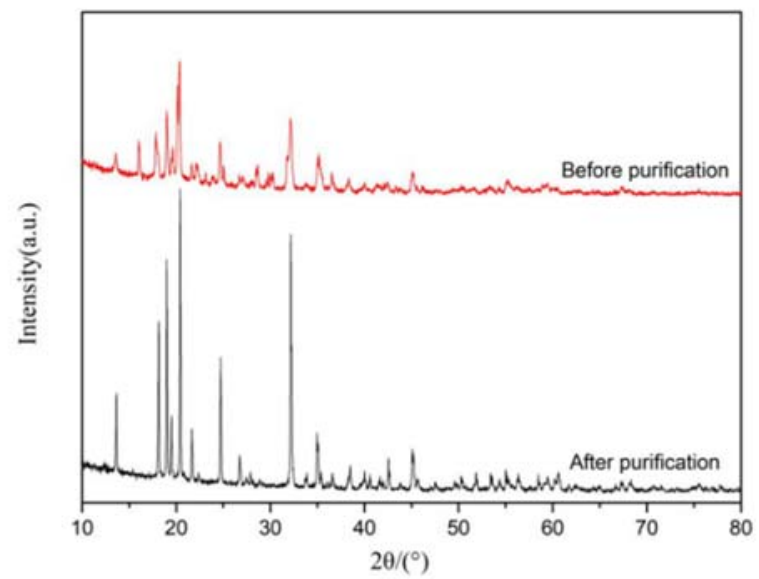

Fig. 3 XRD of two samples 


\subsection{Influence of Temperature on BSF (Biogas Slurry Filtration)}

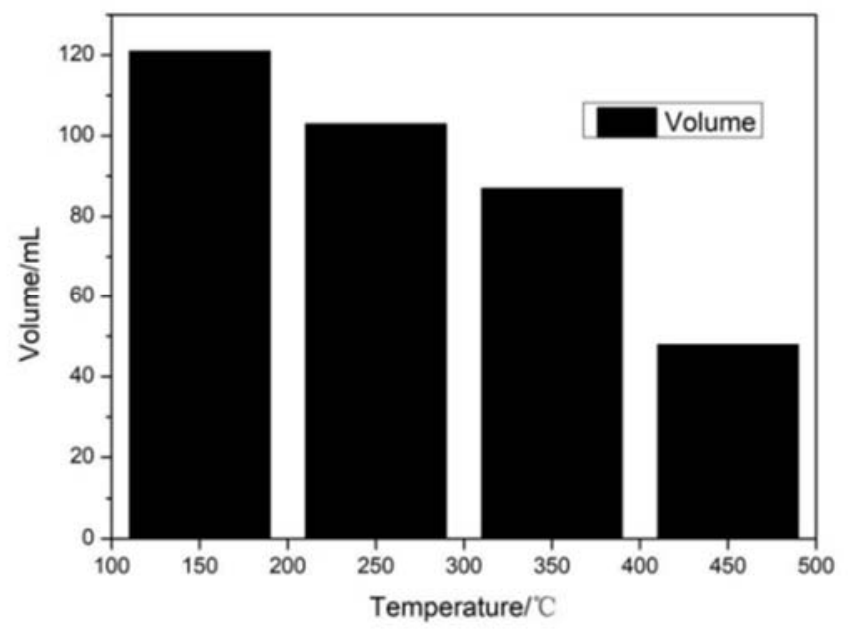

Fig. 4 The effect of temperature on the amount of filtration

Fig. 4 illustrated the different filtering speed of the BSF (biogas slurry filtration) after calcination at different temperature. It can be also found that the volume of BSF decreased with the temperature increasing. It may be the reason that the mixture of poplar sawdust and $\mathrm{FePO}_{4}$ showed smaller volume and higher density after calcination. Thus, the biogas slurry has difficulties passing the filter and the filtration rate is very low.

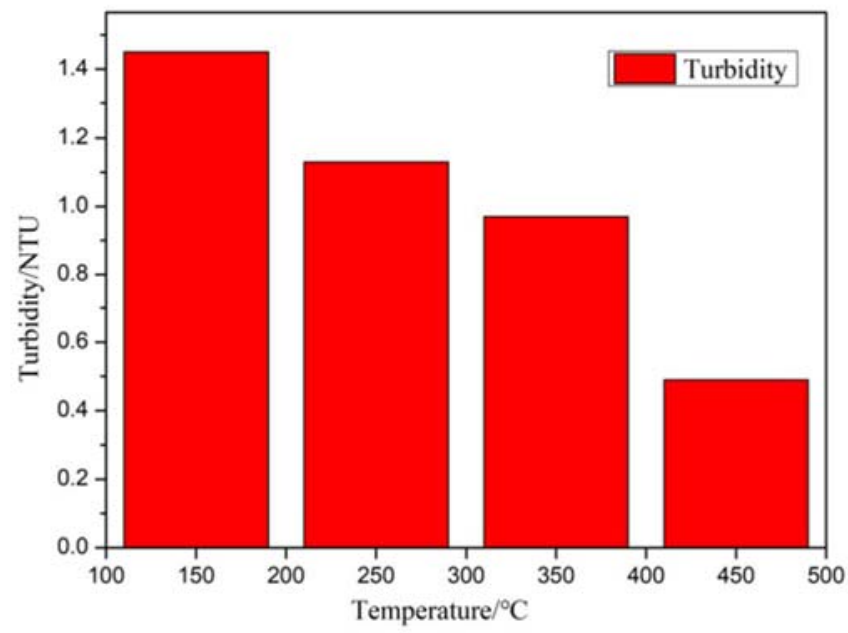

Fig. 5 Effect of temperature on turbidity of BSF

Fig. 5 showed the turbidity of the liquid after BSF and the turbidity of the filtrate decreases as the temperature increases. As the temperature increases, the particle size of poplar sawdust and purified ferric phosphate becomes smaller, the filter gap becomes smaller, and more impurities in the biogas slurry are filtered. After carbonization, poplar's specific surface area increases, which has a fixed effect on heavy metals and other impurities in the biogas slurry [27]. 


\subsection{Influence of $\mathrm{FePO}_{4}$ Addition on BSF}

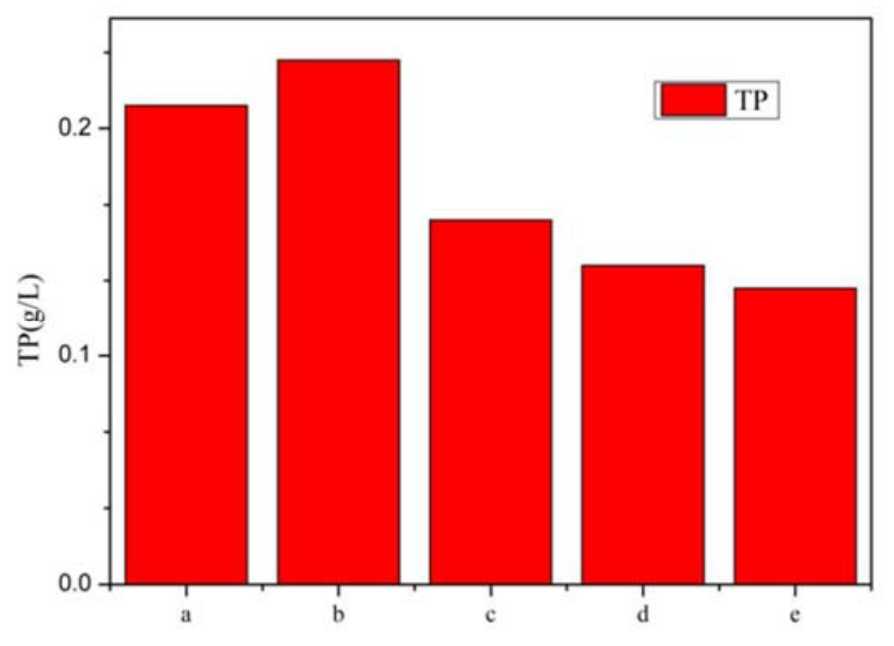

Fig. 6 Effect of temperature on TP in BSF (a) Biogas slurry; (b) $150^{\circ} \mathrm{C}$; (c) $250^{\circ} \mathrm{C} ;(\mathrm{d}) 350^{\circ} \mathrm{C} ;(\mathrm{e}) 450^{\circ} \mathrm{C}$

It can be seen from Fig. 6, the total phosphorus content in the BSF is $0.21 \mathrm{~g} / \mathrm{L}$. the filter do not showed strong adsorption capacity at $150^{\circ} \mathrm{C}$, because the poplar sawdust could not be carbonized while the P content in the filtered filtrate increases. With the increase of temperature, the adsorption capacity of carbonized poplar sawdust increased, and the content of $\mathrm{P}$ in the filtrate gradually decreased. The increase of $\mathrm{P}$ element can promote the growth of plant roots. Therefore, the optimum condition for material carbonization is $150^{\circ} \mathrm{C}$. At this temperature, the starch in poplar sawdust will be modified with less sticky and adsorption, which contributes to the release of $\mathrm{P}$ element [28].

The iron phosphate addition not only improved relatively density with poplar sawdust, accelerate filtering speed. But the acidity of iron phosphate could lower the $\mathrm{pH}$ value of filtrate, contribute to the release of nutrients in the biogas slurry. Moreover, ferric phosphate has a certain heavy metal fixation capacity [29].

\section{Summary}

This study mixed poplar sawdust with the purified phosphating residue. And then grinding, carbonizing were carried out to prepare liquid fertilizer by filtering biogas slurry. We also discussed the possibility of filter material as liquid fertilizer.

The following conclusions can be drawn from the above experiments:

1. The filtrate played an important role in colloid removal, which can be used in drip irrigation in agriculture.

2. The filter material showed heavy metal ions solidification after carbonizing.

3. The filtration volume and turbidity decreased with the temperature increasing, indicating excellent filtering effect.

4. The total phosphorus content reached $0.21 \mathrm{~g} / \mathrm{L}$ at $150^{\circ} \mathrm{C}$ with the biggest BFS.

\section{Acknowledgments}

This work was supported by Shanghai Polytechnic University Graduate Program Foundation (EGD17YJS025), Material Science and Engineering Key Subject of Shanghai Polytechnic University (No. XXKZD1601), and Gaoyuan Discipline of Shanghai-Environmental Science and Engineering (Resource Recycling Science and Engineering). 


\section{References}

[1]. LIU, E.1, LIU, S.2. Process optimization and study of biogas fermentation with a mixture of duck manure and straw. Renewable \& Sustainable Energy Reviews.Vol. 72 (2017), p.439-444.

[2]. JIA, L.1, WANG, D. X.2, ZHAO, G., et al. Biogas Technology in Liaoning Province and Expectation. China Biogas.Vol.35(2017)No.5, p. 75-78.

[3]. QIN, W.1, EGOLFOPOULOS, F.N.2, TSOTSIS, T.T.3. Fundamental and environmental aspects of landfill gas utilization for power generation. Chemical Engineering Journal. Vol. 82(2012) No.1, pp. 157-172.

[4]. DONG, J.1, YING, X.C.2, QIAN, J.X.3, et al. Chemical Fertilizer Pollution and Effect of Biogas Slurry on Crops. Anhui Agricultural Science Bulletin. Vol. 23 (2017) No. 1, p. 52-53.

[5]. PRASAD, D. Y. Biogas generation from bagasse-based paper mills by anaerobic digestion. Journal of Chemical Technology \& Biotechnology. Vol. 51 (2010)No. 4, p. 515-524.

[6]. JIN, H. M.1, CHANG, Z. Z.2, YE, X. M.3, et al. Physical and chemical characteristics of anaerobically digested slurry from large-scale biogas project in Jiangsu Province. Transactions of the Chinese Society of Agricultural Engineering. Vol. 27(2011)No. 1, p. 291-296.

[7]. GUO, Q.1, NIU, D.2, CHENG, H.3, et al. Comprehensive utilizing of biogas residue. Recycling Research. (2008) No. 12, p. 11-15.

[8]. LIU, M. Q.1, XI, Y. G.2, GONG, L. P.3, et al. Key Techniques and Non-Point Source Pollution Control Effect of "Pig-Biogas-Fruit-Fish" Eco-Agriculture Model in Headwaters of Dongjiang River. Journal of Ecology \& Rural Environment. Vol. 26(2010) No. S1, p.58-63.

[9]. CAO, R. K.1, CHEN, H.2, ZHAO, Y. Z.3. Resource Utilization of Biogas Slurry: Current Status and Future Prospects. China Biogas. Vol. 33 (2015) No. 2, p. 42-50.

[10]. ZHANG, W. F.1, MA, W.Q.2, ZHANG, F. S.3, et al Comparative Analysis of the Superiority of China's Phosphate Rock and Development Strategies with that of the United States and Morocco. Journal of Natural Resources. Vol. 20 (2005) No. 3, p. 378-386.

[11]. DU, B.1, RU, Z.G.2, DAN, Z. G.3, et al Overview and prospect of disposal and resource technology of electrolytic manganese residue. Journal of Guilin University of Technology. Vol. 35 (2015) No. 1, p. 152-159.

[12]. ZHANG, Y.1, CHENG, S.2, HAN, W.3, et al. Influence of Prepared Iron Phosphate on Anaerobic Fermentation in Biogas. Journal of Shanghai Second Polytechnic University. Vol. 34 (2017) No. 3, p. 176-182.

[13]. XIONG, X. Y.1, XIONG, T. Q.2, SONG, Q. Q.3, et al. Comprehensive Utilization of Phosphate Residues from Metal Surface Treatment. Metallurgical Power. (2015) No. 2, p. 43-45.

[14]. SUN, S. F.1, HAO, Y. L.2, XU, J. L.3, et al. The national hazardous waste list analysis. Chinese Journal of Environmental Management. Vol. 5 (2013) No.2, p. 46-48.

[15]. KANG, H. C.1, WANG, G. X.2, GUO, H. X. et al. Facile Synthesis and Electrochemical Performance of LiFePO4/C Composites Using Fe-P Waste Slag.Industrial \& Engineering Chemistry Research. Vol. 51(2012)No. 23, p. 7923-7931.

[16]. LIU, Q.1, CHEN, X. J.2, QIAO, Y.M.3, et al. Preparation and electrocatalytic performance of hydroxyl iron phosphate with phosphate sludge. Chinese Journal of Environmental Engineering. Vol. 11 (2017) No. 5, p. 3135-3141.

[17]. SCHIPPER, W. J.1, KLAPWIJK, A.2, POTJER,B.3, et al. Phosphate recycling in the phosphorus industry. Environmental Technology Letters. Vol. 22 (2001). No.11, p. 1337-1345. 
[18]. ZHANG, Z.Y.1, LI, G. X.2, YUAN, J.3, et al. (2016) Effect of corn stalk for filtrating biogas slurry fermented from swine manure. Chinese Journal of Environmental Engineering. Vol. 10 (2016)No. 4, p. 1985-1992.

[19]. PAPURELLO, D.1, SCHUHFRIED, E.2, LANZHINI, A.3et al. Influence of co-vapors on biogas filtration for fuel cells monitored with PTR-MS (Proton Transfer Reaction-Mass Spectrometry). Fuel Processing Technology. Vol. 118(2014) No. 1, p. 133-140.

[20]. MONTEBELlo, A. M.1, MORA, M.2, LOPEZ, L. R.3, et al. Aerobic desulfurization of biogas by acidic biotrickling filtration in a randomly packed reactor. Journal of Hazardous Materials. Vol. 280 (2014) No. 2014, p. 200-208.

[21]. ALMENGLO, F.1, RAMÍREZ, M.2, GOMEZ, J. M.3 et al. Modeling and control strategies for anoxic biotrickling filtration in biogas purification. Journal of Chemical Technology \& Biotechnology. Vol. 91(2016) No. 6, p. 1782-1793.

[22]. DU, L. L.1, ZHANG, Z. Y.2, WANG, M.3, et al. Research on comprehensive integration process and recycling technologies of biogas slurry. Transactions of the Chinese Society of Agricultural Engineering. Vol. 32 (2016) No. S2, p. 207-212.

[23]. JIN, X. C.1, WANG, S. R.2, PANG, Y.3, et al. The influence of phosphorus forms and $\mathrm{pH}$ on release of phosphorus from sediments in Taihu Lake. China Environmental Science. Vol. 24 (2004) No. 6, p. 707-711.

[24]. HUANG,B.1, GAO, S. Y.2, Study on mechanism of wood carbonization - Effect of carbonization method and condition on the property of Chinese fir charcoal. Chemistry \& Industry of Forest Products. Vol. 25(2005) No. S1, p. 95-98.

[25]. ZHOU, J. B.1, DENG, C. J.2, CHEN, J. L.3, et al. Property and Application of Corn Straw Carbonized Products. Journal of Northeast Forestry University. Vol. 36(2008) No. 12, p.59-61.

[26]. ZHANG, X. F.1, YU, X. N.2, ZHOU, H. J.3, et al. Effects of Carbonization Temperature on Biochar Yield and Physicochemical Properties from Wheat-straw. Acta Agriculturae BorealiSinica. Vol. 32(2017) No. 4, p.201-207.

[27]. LIU, L.1. Research on Adsorbing and Immobilizing Heavy Metals of Modified Biochar. Journal of Green Science \& Technology. (2017) No. 16, p.81-84+87.

[28]. XU, B. H.1, LI, H.2. Study of Adsorbent of Modified Wood Chip on Decolour Capability of Printing and Dyeing Wastewater. China Environmental Protection Industry. (2007) No.12, p.3437.

[29]. HE, Q.1, LI, Q.2. Study on Adsorption Properties of Iron Phosphate for Arsenic. Guangzhou Chemical Industry. Vol. 42 (2014) No. 21, p. 65-67+118. 